\title{
A RELAÇÃO FALA - ESCRITA NAS REDES SOCIAIS E A QUESTÃO DOS MULTILETRAMENTOS EM CONTEXTO \\ MULTILINGUE
}

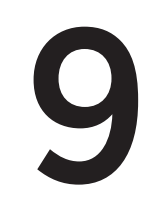

\section{THE SPEAKING - WRITTEN RELATIONSHIP \\ IN SOCIAL NETWORKS AND THE QUES- \\ TION OF MULTILETERACIES IN MULTILIN- \\ GUAL CONTEXT}

\section{ABDULA, Rajabo Alfredo Mugabo}

Doutorando em Linguística e Língua Portuguesa na Universidade Estadual Paulista "Júlio Mesquita Filho" (UNESP). Agência financiadora: Capes.

\section{RESUMO}

Quando falamos acerca escrita nas redes sociais dificilmente se torna separá-la da oralidade. A escrita e a oraldade se fundem nas redes sociais quebrando o conceito tradicional de escrita. As redes sociais tornaram-se espaços para exposição de novos gêneros, de multiletramentos, principalmente quando se fala de sociedades multilingues, onde há influência de uma língua na outra por causa do contato. O objetivo deste trabalho é analisar os casos de letramento digital a partir de dados extraídos do facebook e discutir como a escola deve tratar os casos de letramento digital em sala de aula. O estudo foi feito a partir de conversas do facebook feitas pelos residentes de Quelimane, em Moçambique, que falam a língua local, o echúwabo, e a língua portuguesa.

Palavras-chave: fala e escrita, redes sociais, multiletramentos.

\section{ABSTRACT}

When we talk about writing on social networks it hardly becomes separates it from orality. Writing and orality merge into social networks breaking the traditional concept of writing. Social networks have become spaces for exposing new genres, of multiletramentos, especially 
when speaking of multilingual societies, where there is influence of one language in the other because of the contact. The objective of this work is to analyze digital literacy cases from data extracted from facebook and discuss how the school should handle digital literacy cases in the classroom. The study was based on conversations of facebook made by the residents of Quelimane, in Mozambique, who speak the local language, echúwabo, and the Portuguese language.

Keywords: speech and writing, social networks, multiliteracies.

\section{INTRODUÇÃO}

A fala e a escrita são os dois principais vetores da comunicação humana. Os conhecimentos que adquirimos e caminhos que usamos para a sua transmissão passam, necessariamente, pelo envolvimento destes dois tipos de comunicação. Isso significa dizer que, a maior parte do conhecimento que temos, adquirimos ouvindo os outros ou lendo, e, passamos aos outros falando ou escrevendo. A fala é mais antiga que a escrita, por isso, encontramos estudos que dão conta da invenção da escrita, com descrições do século, lugar, tipo de escrita e todo o processo evolutivo que levou até à escrita que temos hoje. No entanto, o mesmo não acontece com a fala, o único registro que podemos ter é o dia em que uma criança começou a falar. Apesar da fala e da escrita estarem presente na vida diária do ser humano e serem os principais caminhos pelos quais a comunicação é feita, cada uma tem a sua particularidade, o que faz com que não escrevamos como falamos e não falemos como escrevemos. Neste artigo não procuramos discutir com as características de cada uma delas, queremos apenas refletir como elas hoje com o desenvolvimento das tecnologias digitais se cruzam na função mesmo espaço.

A escola é o espaço onde normalmente se dá o ensino da escrita e da leitura, porém, a fala é anterior a escola, ou seja, o aluno tem o seu primeiro contato com a escola falando alguma língua que, em certos casos, para o caso de Moçambique, não é a língua de ensino. A escola procura tratar a fala e a escrita em campos diferentes, todavia, com o advento das tecnologias digitais, sobretudo as redes sociais, a oralidade e a escrita se fundem criando um novo fenômeno na escrita e que, a escola deve saber lidar com ele principalmente quando se trata de contexto multilingue como Moçambique, onde, para além do contato ser entre a oralidade e a escrita, é, também, entre duas ou mais línguas. 
O objetivo deste artigo é (i) analisar os casos de letramento digital a partir de dados extraídos do facebook e (ii) discutir como a escola deve tratar os casos de letramento digital em sala de aula.

Como metodologia, o corpus da pesquisa foi obtido atráves de conversas do facebook feitas em português por usuários residentes em Quelimane - Moçambique, que falam o português como língua oficial e o echuwabo como língua local. Portanto, o critério de seleção dos textos foram: (1) serem textos em português, (2) produzidos por naturais e residente em Quelimane, e (2) que sejam falantes do português e do echuwabo.

Em termos de estrutura, o trabalho começa falando em primeiro lugar da relação fala-escrita, de seguida, letramento e alfabetização, letramento digital, redes sociais, facebook, chat e escrita, o ensino na era digital e, por último, as considerações finais e as referências bibliográficas.

\section{RELAÇÃO FALA - ESCRITA}

A escrita é muito recente comparativamente à existência do homem, é resultado das diversas descobertas que o homem vem fazendo desde os primórdios das civilizações, tendo em vista a preencher as suas necessidades e facilitar o seu desempenho no relacionamento com o outro, e na dinamização do seu processo de desenvolvimento. A língua escrita não pode ser entendida como mera transcrição ou reprodução da fala feita graficamente, o que significa dizer que não escrevemos exatamente como falamos e não falamos do mesmo jeito como escrevemos. A escrita possui regras próprias previamente estabelecidas e jamais substitui a fala, mas as duas formas se complementam.

$\mathrm{Na}$ fala temos a presença do interlocutor, permitindo a utilização de recursos não verbais (paralinguísticos), como a linguagem corporal, facial, entonações diferenciadas e a prosódia. Por outro lado, na escrita, não temos a presença do interlocutor, temos o destinatário do texto que pode ser imaginário. Para a compreensão do conteúdo são usados outros recursos como a pontuação e acentuação gráfica, além de outros recursos gráficos e linguísticos.

Ong (1998) faz distinção entre dois conceitos relacionados com a oralidade; o primeiro ele chama de "oralidade primária" e o segundo de "oralidade secundária". O primeiro está relacionado com a oralidade das culturas intocadas pelo letramento ou por qualquer 
conhecimento da escrita ou da imprensa, inclui também neste grupo as pessoas totalmente não familiarizadas com a escrita. O segundo está relacionado com a atual cultura ligada ao desenvolvimento de alta tecnologia, acesso à comunicação por via de telefone, rádio, televisão, internet e todos aqueles meios eletrônicos cujo funcionamento depende da escrita e da imprensa. O ponto de vista de Ong é que na atualidade não existe cultura de oralidade primária no sentido estrito, na medida em que todas as culturas conhecem a escrita e têm alguma experiência de seus efeitos.

Concordamos com o posicionamento de Ong, porque, na primeira oralidade que é a oralidade primária, a interação é feita fisicamente, é necessário que dois interlocutores ou mais estejam em contato físico para que ela possa ocorrer. Nas sociedades em que a escrita não foi ainda desenvolvida, tudo tende a ser feito oralmente; a transmissão de conhecimentos, informação, valores é feita oralmente e isso passa de geração para geração; a palavra é um grande tesouro, é um bem confiável e que não pode ser traído para não correr o risco de perder toda informação ou conhecimento que a sociedade desenvolveu e precisa ser preservada para que os outros possam ter acesso a ela. A segunda oralidade, que ele denomina de oralidade secundária, é a que se verifica nas sociedades modernas hoje, principalmente nas pessoas que se encontram em centros urbanos em que a própria dinâmica da vida e a necessidade de estar sempre ligados aos acontecimentos propiciam o uso destes instrumentos, fazendo com que as pessoas possam realizar diversas atividades e monitorar o seu andamento sem que seja necessária a presença física.

Contudo, o que nos parece questionável é quando Ong afirma que, atualmente, não exista oralidade primária, ou seja, o nível de desenvolvimento tecnológico que o mundo atingiu cria condições para que assim se afirme; pelo menos é o que tenta transparecer. Mas ao afirmar assim não estaria levar em conta as várias sociedades no mundo que ainda não dispõem destes meios em que todo o seu processo de transmissão de informação é feito por via da oralidade, e que não têm nenhum contato com a escrita. Como devem ser vistos, por exemplo, os grupos tribais que se encontram no interior da África como os Massai ${ }^{1}$ e diferentes outros grupos que não têm acesso à escrita, e que usam outros meios de transmissão de conhecimentos e de valores sociais como o conto, adágios, os ritos de iniciação e toda a estrutura subjacente a uma sociedade oral? Este posicionamento de

\footnotetext{
1. Os Massai são uma população africana seminômade localizada no Quênia e no norte da Tanzânia. Sua origem remonta ao baixo vale do Nilo, ao norte do Lago Turkana (no Noroeste do Quênia). Seu idioma é o Maa e o Suáli, mas também são educados em Inglês. Estima-se que sua população seja de cerca de 800.000 pessoas. Cf. África Tradicional. Disponível em: http://colecaoitan.org/conteudo/pranchas/trajes/Massai.pdf____cesso: 30 de Jul 2018.
} 
Ong parece-nos mais generalizado em função das características de uma sociedade urbana em que o cotidiano das pessoas está associada ao uso das tecnologias para a interação. Com isso não se quer dizer que a tecnologia não tenha chegado às zonas rurais, e nem dizer que todas as pessoas deste meio não são capazes de usá-la com conhecimento como qualquer outra pessoa do meio urbano; há sim uma tendência crescente de acesso à tecnologia, porém, abrange um número pequeno de pessoas. O acesso à escrita não é ainda comum para todas as sociedades, e o seu processo histórico leva-nos a compreender que "o acesso à palavra escrita é cultural e dependente do valor associado às práticas de leitura e escrita ao longo da socialização dos falantes" (MATENCIO, 1994, p. 43).

A partir deste ponto de vista, pode se afirmar que a questão da escrita está ligada à história, ao modo de vida e ao valor simbólico que ela representa nos diferentes povos. De acordo com Marcuschi (2003, p. 31), o "... estudo do letramento deve ser vinculado a aspectos etnográficos, pois ele se dá numa estreita relação com a cultura". Diz ainda que "...todos os povos, indistintamente têm ou tiveram uma tradição oral, mas relativamente poucos tiveram ou têm uma tradição escrita" (MARCUSCHI, 1997, p. 2).

\section{ALFABETIZAÇÃO E LETRAMENTO}

A alfabetização e o letramento são conceitos que muitas vezes se confundem devido à imagem com a qual os dois estão relacionados. Contudo, existem diferenças que fazem com que estes dois conceitos sejam tratados de maneiras diferentes, o que podemos ver ao se fazer uma abordagem separada.

\section{Alfabetização}

Sempre que se fala em alfabetização associa-se à escola, o que leva a entender que este processo é exercido neste espaço, ou então é lá onde a sua prática é mais acentuada. Segundo Soares (2007), o termo "alfabetização" etimologicamente, significa: levar à aquisição do alfabeto, ou por outra, ensinar a ler e a escrever. Sendo assim, a essência da alfabetização é a aquisição do código alfabético e ortográfico através do desenvolvimento das habilidades de leitura e de escrita. Para Freire (1985, p. 14) "a alfabetização não é um jogo de palavras; é a consciência reflexiva da cultura, a reconstrução crítica do 
mundo humano, a abertura de novos caminhos (...). A alfabetização, portanto, é toda a pedagogia: aprender a ler é aprender a dizer a sua palavra".

\section{Letramento}

O termo "letramento" é recente na Linguística e na educação, e tem sido utilizado para dar referência ao conceito que diz respeito a capacidades de leitura e de escrita. Com isso pretende-se distingui-lo de alfabetização por não ter em conta o grau de escolaridade a que esta, tradicionalmente, estava ligada. De acordo com Soares (1998), este termo surgiu a partir da necessidade de se observar o estado de quem sabe ler e escrever, em contraposição a uma preocupação anterior, que se voltava apenas para o estado ou condição de analfabetismo. Querse com isso fazer entender que o letramento não se resume apenas em aprender a ler e a escrever, mas, sim, em fazer o uso efetivo da leitura e da escrita adequando-se às necessidades sociais. O letramento não só se restringe ao ambiente formal, mas pode também ser desenvolvido em ambiente informal desde que o indivíduo tenha contacto com práticas; como afirma Marcuchi, "é um processo de aprendizagem social e histórico da leitura e da escrita em contextos informais e para usos utilitários [...] um conjunto de práticas" (MARCUCHI, 2003, p. 22). Kleiman (1995, p. 19) diz que "Podemos definir hoje o letramento como um conjunto de práticas sociais que usam a escrita, enquanto sistema simbólico e enquanto tecnologia, em contextos específicos, para objetivos específicos". Segundo Soares,

\footnotetext{
os conceitos de letramento que enfatizam sua dimensão social fundamentam-se ou em seu valor pragmático, isto é, na necessidade de letramento para o efetivo funcionamento da sociedade (a versão "fraca"), ou em seu poder "revolucionário", ou seja, em seu potencial para transformar relações e práticas sociais injustas (a versão "forte") (SOARES, 2002 p.78).
}

Vê-se, todavia, que o letramento não se resume à mera capacidade de conhecimento gramatical ou à capacidade de escrever seu nome, fazer uma cópia ou escrever bilhete; é preciso ter em conta o contexto no qual se escreve, o que se pretende alcançar com o que se escreve e quem são os destinatários do que se escreve. Podemos assim dizer que o letramento não só se consubstancia no uso da sintaxe, mas, acima de tudo, requer o uso da pragmática. 
Analisados os dois conceitos - alfabetização e letramento, podemos, nas palavras de Soares concluir que,

alfabetização é a ação de ensinar/aprender a ler e a escrever (...) o Letramento é o estado ou condição que adquire um grupo social ou um indivíduo como conseqüência de ter-se apropriado da escrita e de suas práticas sociais (SOARES, 2002a, p.39-47).

\section{LETRAMENTO DIGITAL}

A prática do letramento nos dias de hoje ganhou outra feição como resultado do desenvolvimento científico e tecnológico. Se o letramento já era associado à escrita, hoje não só é visto nesse sentido, mas também no espaço onde ele ocorre; ou seja, é entendida como o processo que envolve a escrita em estreita relação com o meio social onde ela é desenvolvida. $\mathrm{O}$ acesso à internet e às redes sociais cria condições para que esta prática possa ser exercida em função deste novo espaço que é o ciberespaço. O facebook, por exemplo, é um desses lugares onde o letramento é exercido.

Para melhor compreensão deste fenômeno, é relevante conhecer o que são redes sociais e como elas funcionam. É sobre isso que nos propomos a tratar a seguir.

\section{Redes sociais}

O mundo tende cada vez mais a se desenvolver tecnologicamente, e esse desenvolvimento tem impacto direto nas vidas das pessoas. $\mathrm{O}$ nível de desenvolvimento tecnológico que se atingiu era difícil de se imaginar há 30, 20 anos atrás tendo em conta a velocidade com que as coisas acontecem. Esse desenvolvimento permitiu que a dinâmica dos serviços fosse acrescida, trazendo ganhos significativos em termos de tramitação de documentos e de redução da burocracia, por exemplo; mas também, permitiu o encurtamento de distância entre pessoas que se encontram em espaços geográficos distantes, principalmente com o advento das redes sociais. Para Aguiar,

Redes Sociais são, antes de tudo, relações entre pessoas, estejam elas interagindo em causa própria, em defesa de outrem ou em nome de uma organização, mediadas ou não por sistemas informatizados; são métodos de interação que 
sempre visam algum tipo de mudança concreta na vida das pessoas, no coletivo e/ou nas organizações participantes (AGUIAR, 2007, p.2).

Atualmente vários outros espaços têm surgido dentro das redes sociais, que vêm facilitar ainda mais a comunicação entre as pessoas, como é o caso do facebook. Essas ferramentas emergentes, como diz Recuero (2009), são marcadas pela existência de atores, que são as pessoas individualmente que interagem mutuamente, e os grupos que são criados dentro desses espaços e que os indivíduos fazem parte e, toda a opinião ou conteúdo das mensagens devem estar de acordo com as regras do grupo que são previamente definidas.

Segundo Recuero (2009), as redes sociais que são desenvolvidas na atualidade são aquelas expressas a partir das interações entre os atores sociais. São redes cujas conexões entre os nós emergem através das trocas sociais realizadas pela interação social e pela conversação através da mediação do computador. Nas redes de filiação, há apenas um conjunto de atores, mas são redes de dois modos, porque é estudado um conjunto de eventos aos quais um determinado ator pertence. Para Recuero (2009), chama-se rede de dois modos porque são medidas duas variáveis: além dos atores-indivíduos, são observados os eventos. Cada um desses eventos é, ainda, um elemento de conexão de um conjunto de atores. As redes de filiação seriam, assim, constituídas de dois tipos de nós: os atores e os grupos.

As redes sociais possibilitam que as informações cheguem simultaneamente para todos os que se encontrem ligados ou que pertençam ao grupo e que estejam conectados à internet. Para Santaella (2003), "uma rede acontece quando os agentes, suas ligações e trocas constituem os nós e elos de redes caracterizadas pelo paralelismo e simultaneidade das múltiplas operações que aí se desenrolam" (SANTAELLA, 2003, p.89). Muitas vezes elas permitem que reuniões ou conferências possam ser realizadas mesmo que as pessoas não estejam presentes fisicamente; é o mundo virtual, um mundo que procura ter as pessoas mais próximas uma das outras através da conexão por via de um computador ou mesmo telefone celular ligado à internet.

Sempre que o computador estiver ligado às redes digitais cria-se a possibilidade para que se troquem mensagens entre duas ou mais pessoas, ou para que participem nas conversas dentro de grupos, participem de conferências sobre os mais diversos temas, tenham acesso às informações partilhadas, construam juntos mundos virtuais puramente lúdicos - ou mais sérios -, constituam uns para os outros 
uma imensa enciclopédia viva, desenvolvam projetos políticos, amizades, cooperações.

Um dos espaços que muita gente tem em mente quando se fala de redes sociais é o facebook. Novo em termos de criação, mas que ganhou um grande número de usuários em pouco tempo e é considerada a maior rede social. Vejamos então como o facebook apareceu e se tornou um lugar de acesso de massas.

\section{Facebook}

O facebook é um instrumento de interação indispensável para a maioria das pessoas de hoje, principalmente os jovens. Este instrumento foi criado em 2004, pelo americano Mark Zuckerberg, ainda na fase em que era estudante da Universidade de Harvard. Ele criou o facebook com objetivo inicial de facilitar a interação entre os alunos da faculdade, como um meio de estreitar as relações entre os membros desta classe, como explica Recuero:

O foco inicial do Facebook era criar uma rede de contatos em um momento crucial da vida de um jovem universitário: o momento em que este sai da escola e vai para a universidade, o que, nos Estados Unidos, quase sempre representa uma mudança de cidade e um espectro novo de relações sociais. O sistema, no entanto, era focado em escolas e colégios e, para entrar nele, era preciso ser membro de alguma das instituições reconhecidas (RECUERO, 2009, p.171).

Atualmente o facebook não é apenas um instrumento para os jovens estudantes das universidades dos Estados Unidos, das escolas e dos colégios; é um instrumento para todas as universidades do mundo, para as instituições públicas e privadas, para o comércio, para a política, em suma, para toda a sociedade. Com sua natureza de fácil acesso e a rapidez que cria para transmissão de mensagens tem vindo a ganhar cada vez mais adeptos, principalmente porque é possível acessá-lo por via de telefone celular. Assim, quem se encontra fora de casa, na rua, na praia ou em qualquer outro lugar, pode acessar e interagir com as mais diversas pessoas que estiverem conectadas.

Pelo fato de se poder criar vários grupos no facebook, torna-se ainda maior a presença de pessoas conectadas a todo o momento, porque, nesses grupos, podem ser compartilhados textos, livros, eventos, aulas, e também é um bom lugar para se fazer negócios através 
de publicações de artigos à venda. É um instrumento que tem sido explorado pelos políticos, principalmente em épocas de campanha eleitoral, fazendo dele um meio para transmissão de mensagens aos eleitores, para receber opiniões, e fazer chegar com maior rapidez a sua mensagem a um número grande de pessoas. Uma das formas de interação no facebook é através do chat, onde a escrita vai ganhar suas formas peculiares diferenciando-se da escrita tradcional, como podemos ver a seguir.

\title{
O CHAT E A ESCRITA
}

Se a escrita e a oralidade ocupam espaços diferentes no campo da sua realização, em salas de bate-papo chat encontramos um casamento entre eles quase perfeito. Há uma presença significativa de marcas da oralidade na escrita, o que faz com que o texto seja diferente da tradicional forma da escrita, que passa pela noção e aplicação de regras pré-estabelecidas de como deve ser um texto escrito; e no chat, a escrita acaba fugindo a essa regra do texto escrito. Nesse espaço, as pessoas escrevem como se estivessem falando, como se o seu interlocutor estivesse à sua frente e precisasse ver e perceber todas as manifestações existentes em função da conversa que está a decorrer. $\mathrm{Na}$ verdade, o que aparece neste tipo de conversas é a fala que é materializada em forma de texto, fazendo convergir a fala e a escrita no mesmo espaço, como se pode entender no parágrafo que se segue:

\begin{abstract}
A "fala virtual" se materializa em um texto escrito, porque se organiza estruturalmente na forma escrita, utilizando-se do código alfabético escrito e suas regras de combinação para formar sequências de signos, que darão origem aos enunciados, textos e discursos. E é um texto falado porque se utiliza da estrutura da fala, uma vez que se representam as palavras da forma coloquial, utilizando-se de gírias, onomatopeias; porque é marcado pela espontaneidade, pela sincronia (ALMEIDA, 2011. p. 39).
\end{abstract}

Dentro deste prisma, não se pode olhar este tipo de texto como apenas um texto escrito, porque encontramos marcas significativas da oralidade, nem se pode olhar como um texto oral, porque ele aparece por meio da escrita. Como anteriormente se afirmou, é um casamento entre as duas modalidades e deve ser tratado como tal, principalmente porque nos leva a outro tipo de análise. Trata-se de um fenômeno novo, um fenômeno com que nós devemos nos habituar a conviver, porque o acesso à tecnologia torna-se cada vez maior, fazendo com que as 
conversas, que geralmente eram feitas por meio da oralidade ou escrita através de cartas e bilhetes, passem a ser feitas por via da internet, permitindo que o oral e o coloquial apareçam dentro da escrita. Este fenômeno, de acordo com Catala, "relançam novos diálogos e novos espaços que obviamente requerem ser renovados e inovados como resposta a uma maior velocidade na expressão e agilidade de comunicação" (CATALA, 2009. p. 15).

Difícil é saber até que ponto este fenômeno de presença do oral no escrito irá transformar o sistema linguístico, em que há uma separação entre o escrito e o oral. Parte-se de uma visão dicotomizada entre o escrito e o oral, como modalidades totalmente desconectadas. $\mathrm{Na}$ verdade, essa visão é fortemente questionada, e hoje defende-se uma visão gradual, em que manifestações específicas se localizam em algum ponto específico de uma escala que vai de textos com concepção oral e meio de realização oral a textos com concepção escrita e meio de realização escrita.

A própria existência de textos híbridos como os que encontramos no facebook é prova de que não se trata de realidades totalmente separadas. Com o desenvolvimento tecnológico e a expansão cada vez maior do acesso à internet mostram claramente que essa convivência entre o oral e o escrito no mesmo texto tende a enraizar-se e, portanto, torna-se necessário avançar mecanismos novos para o seu estudo.

\section{OS MULTILETRAMENTOS}

Vivemos numa sociedade pluralista com diferentes valores socioculturais e que esses valores serão refletidos nos textos. Estamos numa fase em que a escola deve ter em conta conceitos como multilinguismo, multissemiose e abordagem pluralista da cultura. Os textos representam diferentes modalidades e gêneros. Sendo assim, não podemos falar de multiletramentos sem falar de multiculturalidade. Foi chamado de multiletramentos "para abranger esses dois 'multi' - a multiculturalidade característica das sociedades globalizadas e a multimodalidade - dos textos por meio dos quais a multiculturalidade se comunica e informa" (ROJO; MOURA, 2012, p. 13).

As diferentes modalidades de textos sempre existiram, mas é, sobretudo, com o advento das novas tecnologias digitais que mais se registra a multiplicidade de linguagens o que nos leva a falar em multiletramentos. Os multiletramentos estão associados ao uso de tecnologias de comunicação e informação, como afirmam Rojo e Moura: 
Trabalhar com multiletramentos pode ou não envolver (normalmente envolverá) o uso de novas tecnologias de comunicação e de informação ("novos letramentos"), mas caracteriza-se como um trabalho que parte das culturas de referência do alunado (popular, local, de massa) e de gêneros, mídias e linguagens por eles conhecidos, para buscar um enfoque crítico, pluralista, ético e democrático - que envolva agência - de textos/discursos que ampliem o repertório cultural, na direção de outros letramentos [...] (ROJO; MOURA, 2012, p. 08).

Os multiletramentos terão, assim, relação com o meio, ou seja, envolvem os valores culturais na construção de textos através dos quais os sujeitos se comunicam e se informam, que são as novas tecnologias de informação e comunicação. Ao falarmos de tecnologias digitais e novas modalidades de escritas que surgiram como fruto desse avanço tecnológico, os multiletramentos terão relação com os novos hipertextos. De acordo com Rojo e Moura, os multiletramentos e os novos hipertextos apresentam as seguintes características:

Eles são interativos, mais que isso, colaborativos; (2) eles
fraturam e transgridem as relações de poder estabelecidas,
em especial as relações de propriedade (das máquinas,
das ferramentas, das ideias, dos textos) [...]; (3) eles são
híbridos, fronteiriços, mestiços (de linguagens, modos,
mídias e culturas) (ROJO; MOURA, 2012, p. 23).

No contexto multilingue, os multiletramentos para além de transportarem marcas culturais, passarão a transportar marcas linguísticas. Os falantes que têm a língua materna diferente da língua de ensino terão a tendência de transportar elemenotos da sua língua materna para a língua de ensino. Esse é o problema que a escola como espaço social deve ter tendo em conta para que encontre mecanismos pedagógicos aceitáveis capazes de reforçar o seu papel de espaço de formação e de socialização. É sobre esse e outros papeis que a escola deve ter que iremos falar de seguida, tendo como ponto de partida os dados obtidos do facebook.

\section{O PAPEL DA ESCOLA}

Tendo em conta os fenômenos da escrita que ocorrem nas redes sociais, a questão que se coloca é a seguinte: qual é o papel da escola e como a escola deve trabalhar esses casos em sala de aula? Qual será 
a reação do professor ao se deparar com as formas de escrita usada nas redes sociais em um texto do aluno em sala de aula? Sabemos que o desenvolvimento da tecnologia digital é irreversível e os alunos encontram nas redes sociais alternativas para a prática da atividade da escrita. Todavia, como se viu anteriormente, a prática da escrita nas redes sociais se difere da escrita tradicional, é uma escrita que incorpora grandes marcas da oralidade. É importante que a disciplina de língua portuguesa, e não só, faça proveito da escrita feita nas redes sociais para incentivar o aluno a ganhar o gosto pela escrita e pelo conhecimento da língua. Para tal, a escola deve valorizar os multiletramentos, as diferentes formas de escritas que os alunos trazem influenciados pelos meio social em que estão inserido, e hoje, esse meio social engloba também os ciberespaços. É sobre essa questão que iremos falar a seguir através da análise do material extraído no facebook e a análise de como o professor de língua portuguesa pode usar em sala de aula. As conversas foram feitas por falantes da língua portuguesa e da língua echúwabo residentes em Quelimane.

Vejamos os seguintes exemplo e como o professor de língua portuguesa pode trabalhá-los em sala de aula:

1. "tentei até nos $300 \mathrm{mt}$, ele disse que estava a nhamelar da sua boa vontade"

Nyamelar - do verbo onyamela: seguir escondidamente para, aproveitar, tirar proveito de. $\mathrm{de}^{\prime}$.

Nesta frase nyamelar corresponde a 'aproveitar ou tirar proveito

2. "... e vi umas sapatilhas, gostei ele fazia por $500 \mathrm{mt}$ tentei loguelar com o

vendedor"

Loguelar - do verbo ologela: interceder, implorar para, invocar para, suplicar

para, negociar.

Nesta frase loguelar corresponde a 'negociar'.

3. "laa...vocês zuzumaram, porquê não esperaram um pouco?"

Zuzumar - do verbo ozuzuma: estar preocupado, estar atarefado, estar atrapalhado, não saber o que fazer ou dizer, estar confuso, estar em apuros, estar em dificuldade. 
Nesta frase, zuzumar tem como correspondente 'estar atrapalhado ou estar confuso'.

O professor pode usar as três frases ao falar de verbos e de formação de palavras, por exemplo. Ele pode explicar aos alunos que nyamelar, loguelar e zuzumar são verbos da língua echúwabo e que ao serem usado no português obedeceram à flexão do português; e são palavras derivadas por sufixação. Isso fará com que o aluno não só conheça os verbos do português, mas também conheça os verbos da sua língua materna e o processo que ocorreu ao entrarem em contato com o português.

O mesmo deve acontecer ao falar dos substantivos, recorrendo exemplos tais como:

4. "um me parece $k$ ta faltar um ou duas ou 3...gastronomia. Cade a mucapata e agalinha k so nos sabemx faze -la"

5. "Falta mutxoro, matago, mikathe tha mbuga?"

6. "so espero $\mathrm{k}$ nao tenha ficado de fora a mucapata,o frango a zambeziana,o mucuane de mandioca, a sanana, e pra nao falar do mucadje k tambem sinto saudade".

O professor pode usar os exemplos e dizer que mucapata, mutxoro, matago, mikathe, mbuga, sanana, mucane e mucadje são substantivos. Ele pode ensinar os seus correspondentes na língua portuguesa para os casos em que é possível, como são os casos de mbuga que signifa arroz, mucuane que sigrnifica verdura, apenas para ilustrar alguns.

Ele também pode usar exemplos como os que se seguem ao falar de interjeiçõos.

7. "ijiiii parabensssss maninho pelo vosso dia"

8. "huuuuu!!!! k alivio. as biras vao xi arepender d xerem feitas. né?"

9."o dia nem comexou a dia ja existem planos das birras iiiiiiiiiiiiiiiiiiiiiiii ucesssss".

10. "Ishii bangui... Agora vamos para as Cer...jas. Frt abraço irmão". 
O professor poderá explicar aos alunos que ijiii, huuuu, iiiiii e ishiii que geralmente são usados pelos falantes do echúwabo, são interjeições, e explicar que função elas desempenham nas frases.

Estes e tantos outros exemplos podem ser muito bem explorados pelo professor em sala de aula e não se limitar apenas em corrigí-los e condená-los por produzirem estes tipos de frases. É preciso que o prefessor seja criativo e saiba explorar os diferentes cenários que a língua portuguesa se expõe ao entrar em contato com outras línguas, principalmente na era em que nos encontramos, a era das tecnologias digitais e das redes sociais.

\section{CONSIDERAÇÕES FINAIS}

Neste trabalho procuramos discutir a questão da escrita nas redes sociais feitas em contexto multilingue. Ao analisarmos a oralidade e a escrita vimos que a oralidade é mais antiga que a escrita. A escrita foi inventada mais tarde e aprimorada para responder às necessidades do próprio homem; porém, há sociedades que ainda não fazem o uso da escrita. Quando falamos do mundo digital em que o uso da internet tem um papel fundamental na relação e interação entre as pessoas, a questão da oralidade e da escrita ganha outra feição, justificada pelo fato de coabitarem o mesmo (ciber) espaço.

Numa sociedade onde coabitam duas ou mais línguas, é frequente que este fenômeno de presença do oral no escrito se verifique na interação entre os falantes dessas línguas, o que permite a interferência de um sistema linguístico no outro. Isso acontece, por exemplo, com os falantes do português na cidade de Quelimane pelo fato de, para além de português, serem falantes do echuwabo. Essa influência é muito notória nas conversas feitas nas redes sociais como o facabook. Particularidades como estas e dos multiletramentos em geral devem ser tratados com especial atenção pelas escolas principalmente na disciplina de língua portuguesa. O professor não deve condenar os alunos pela escrita que produzem como as que se verificam nas redes socias, pois, elas representam a sua identidade, o conhecimento que têm sobre a língua. É preciso acolher essas formas diferentes de escrita e encontrar um melhor direcionamento tendo em conta o cumprimento dos objetivos que a escola previamente definiu, que passará pela boa formação do aluno para que possa responder os desafios que o país e o mundo apresentam. 


\section{REFERÊNCIAS BIBLIOGRÁFICAS}

AGUIAR, S. Redes Sociais na Internet: Os desafios à pesquisa. Rio de Janeiro: 2007

ALMEIDA, A. Caracterização da escrita no ciberespaço: convergências e divergências em salas de bate-papo brasileira (Tese). Unesp. Araraquara. 2011

CATALA, S.A. Siglo XXI: Nuevos Tiempos, Nuevas Palabras, Nuevas Conceptualizaciones, Nuevos Códigos. In ALVES, leda Maria et al. (Org). Os Estudos Lexicais em Diferentes Perspectivas. Volume I. Sao Paulo : FFLCH/USP, 2009.

FREIRE, P. Educação e mudança. 9. ed. Rio de Janeiro: Paz e Terra, 1983.

KLEIMAN, A. (Org.). Os significados do letramento: uma nova perspectiva sobre a prática social da escrita. Campinas: Mercado de Letras, 1995. p. 15-61.

MARCUSCHI, L. A. Da fala para a escrita: atividades de retextualização. 4. ed. São Paulo: Cortez, 2003.

Oralidade e escrita. In: Signóptica. 9: 119-145, jan./dez. de 1997. p. 2.

MATENCIO, M. L. M. Leitura Produção de Textos e a Escola: Reflexões sobre o Processo de Letramento. Campinas, SP: Mercado de Letras, 1994.

ONG, W. J. Oralidade e cultura escrita: a tecnologização da palavra. Campinas: Papirus, 1998.

RECUERO, R. Redes Socias na Internet. Porto Alegre: Sulina, 2009.

ROJO, R; MOURA, E. Multileramentos na escola. São Paulo: Parábola Editorial, 2012.

SANTAELLA, Lucia. Culturas e artes do pós-humano: De cultura das mídias à cibercultura. São Paulo: Paulus, 2003.

SOARES, Magda. Alfabetização e letramento. 5. ed. São Paulo: Contexto, 2007.

Letramento: Um tema em três gêneros. 2. ed., 5. reimpr. Belo Horizonte: Autêntica, 2002.

Recebido em: 20/10/2018

Aceito em: 20/11/2018 